\title{
Primary Gleason Pattern
}

National Cancer Institute

\section{Source}

National Cancer Institute. Primary Gleason Pattern. NCI Thesaurus. Code C48603.

The most prevalent Gleason pattern in a prostate biopsy or prostatectomy specimen.

The Gleason score is defined by adding the most prevalent (primary) and second most prevalent (secondary) patterns. 